\title{
The Relationship Between Androgen Receptor, Components of Tumour Microenvironment and Survival in Breast Cancer Molecular Subtypes
}

\author{
Fadia Gujam ${ }^{1 *}$, Katie Dickson¹, Pamela McCall ${ }^{1}$, Donald McMillan² and Joanne Edwards ${ }^{2}$ \\ ${ }^{1}$ Institute of Cancer Sciences, College of Medical, Veterinary and Life Sciences-University of Glasgow, UK \\ ${ }^{2}$ Academic Unit of Surgery, College of Medical, Veterinary and Life Sciences-University of Glasgow, UK
}

Submission: June 25, 2018; Published: July 16, 2018

"Correspondence Address: Fadia JA Gujam, Institute of Cancer Sciences, College of Medical, Veterinary and Life Sciences, University of Glasgow, Glasgow, G61 1QH, UK, Email: fadiajoumaagujam.gujam@glasgow.ac.uk

Abstract

Background: The androgen receptor (AR) pathway has emerged as a potential therapeutic target in breast cancer with increased attention to provide biological insight into triple negative breast cancer (TNBC). The present study assessed the role of AR within the tumour microenvironment in patients with invasive ductal breast cancer.

Methods: Immunohistochemical analysis of AR was performed on a breast cancer tissue microarray of 850 patients. These results were correlated with clinicopathological data and cancer specific survival (CSS).

Results: Positive AR expression was seen in $75 \%$ of luminal A, $70 \%$ of B, $47 \%$ of Her2 like and $31 \%$ of TNBC. AR was associated with invasive grade $(p<0.001)$, estrogen receptor / progesterone receptor $(p<0.001)$, molecular subtypes $(p<0.001)$, necrosis $(p<0.001)$, reduced inflammation $(\mathrm{p}<0.001)$, and increased tumour budding $(\mathrm{p}=0.001)$. AR was consistently associated with tumour budding in molecular subtypes; luminal A $(\mathrm{p}=0.022)$, Her2 like $(\mathrm{p}=0.035)$ and TNBC $(\mathrm{p}=0.034)$. In TNBC, AR was associated with poor CSS $(\mathrm{P}=0.013)$.

Conclusion: AR may be an important regulator of tumour budding in breast cancer. AR is a potential prognostic marker and therapeutic target for patients with TNBC.

\section{Background}

Breast cancer is considered as a hormone driven cancer [1]. The majority of breast cancers are slow growing and convey good clinical outcome [2], however a subset acquires an aggressive phenotype in terms of molecular, genotypic, and phenotypic features resulting in multiple subtypes and classifications of breast cancer [3,4]. Historically, breast cancer has been classified as ER (oestrogen receptor) positive or negative based on expression or lack of expression of ER or PR (progesterone receptor). Based on cell-type and molecular signature, molecular subtypes have emerged as into luminal A, luminal B, Her2 (human epidermal growth factor receptor 2) like and basal-like or triple negative breast cancer (TNBC) [3].

The luminal subtypes have good prognosis and usually treated with ER targeted therapy. Her2 like is treated by Her2targeting antibodies Trastuzumab with significant improvement in survival [5]. TNBC exhibit aggressive features and associated with increased mortality. With the exception of EGFR targeted therapy [6], to date there is no targeted treatment for this group.
Therefore, there is an increasing need to identify a biomarker as a therapeutic target for those patients. Androgen receptor (AR) (a steroid hormone nuclear receptor) has more recently emerged as a possible biomarker for cancer treatment in ER positive patients that fail endocrine therapy and in TNBC patients [7].

$\mathrm{AR}$ is even more widely expressed in breast cancer than ER or PR, with more than 70\% invasive cells expressing AR [8]. The magnitude and direction of association between AR expression and clinical outcome in both ER-positive and ER-negative breast cancer is still unclear. In addition, gene expression profiling of breast cancer suggests a significant functional role for AR in multiple subtypes of breast cancer [4,9]. Preclinical studies also have demonstrated that androgens can lead to proliferation of AR-expressing breast cancer cell lines and promote tumour formation in animal models [10]. The proposed mechanism for these findings is that that signalling through AR replaces oestrogen-dependent signalling as the major determinant of steroid-related gene expression. This signalling can exert a 
stimulatory effect through the androgen responsive element, thereby stimulating transcription of steroid responsive genes [11].

Clinical data have also shown contradictory results on the prognostic power of AR in breast cancer [12-18]. Therefore, the role of androgen and androgen receptor pathway in breast cancer growth and progression remain undefined. In addition, it is increasingly apparent that cancer progression and outcomes in breast cancer are not solely dependent on characteristics of the tumour but also on the interactions between the tumour and the host [19]. Components of tumour microenvironment including tumour inflammatory infiltrate and tumour budding are now increasingly recognised that they play a key role in cancer progression and survival [20,21]. Therefore, the aim of this study was to examine the relationship between androgen receptor, clinicopathological characteristics, and components of the tumour microenvironments outcome across the molecular subtypes of patients with invasive ductal breast cancer.

\section{Materials and Methods}

\section{Patient Cohort Characteristics}

Patients presenting with invasive ductal breast cancer at Glasgow Royal Infirmary, Western Infirmary and Stobhill Hospital between 1995 and 1998 with formalin-fixed paraffin embedded blocks of the primary tumour available for evaluation were studied $(\mathrm{n}=850)$. The study was approved by the Research Ethics Committee of the West Glasgow University Hospitals NHS Trust. Clinicopathological data including age, tumour size, tumour grade, lymph node status, type of surgery and use of adjuvant treatment (chemotherapy, hormonal based therapy and/ or radiotherapy) were retrieved from the routine reports. Tumour grade was assigned according to the Nottingham Grading System. ER and PR status were assessed on tissue microarrays (TMAs) using immunohistochemistry (IHC) with Dako (Glostrup, Denmark) ER antibody and Leica (Wetzlar, Germany) PR antibody. Her2 status were assessed visually using TMAs as previously described [22].

Section haematoxylin and eosin (H\&E) slides for the 752 patients were used to score local inflammatory infiltrate according to Klintrup-Makinen (KM) criteria. KM scoring of slides was carried out as previously described. Briefly, tumours were scored on four-point scores based on appearances at the tumour invasive margin. A score of 0 signified that there were no inflammatory cells at tumour's invasive margin; score 1 indicated a mild and patchy inflammatory cell; score 2 denoted a prominent band-like inflammatory reaction at the invasive margin; and score 3 revealed a florid cup-like inflammatory infiltrate at the invasive edge [23].

Full-section H\&E slides were also used to score the tumour stroma percentage (TSP) [24] and tumour budding [25] as previously reported. Briefly, at $5 \mathrm{x}$ magnification, an area representative of the tumour invasive margin was selected, and then a single field of 10x magnification was examined, ensuring that tumour cells were present at all four sides of the image and the area of stroma was calculated as a percentage. Tumour budding was evaluated as clusters of 1-5 cancer cells within the tumour microenvironment bud.

The molecular subtypes were defined as follows: Luminal A: oestrogen (ER) and/or progesterone receptor (PR) positive, Her-2 negative or low proliferative index (<15\%); Luminal B: hormone receptor positive, Her- 2 positive or high proliferative index (> 15\%); Her-2 subtype: Her-2 positive and hormone receptor negative, any proliferative index; and triple negative: Her-2 negative, hormone receptor negative, any proliferative index.

\section{Immunohistochemistry}

Optimisation of the antibody utilised was demonstrated using a single band of appropriate size, on a western blot and immunohistochemistry was performed. Antibody validation for AR was carried out as previously described [26]. IHC was conducted in triplicate on tissue microarrays (TMAs). Slides were dewaxed in xylene and rehydrated through graded alcohol. For total AR, antigen retrieval was performed under pressure in a solution of Tris-EDTA buffer (10 mM Trizma Base, $0.25 \mathrm{mM}$ EDTA), $96^{\circ} \mathrm{C}$ for $5 \mathrm{~min}$. Endogenous peroxidase were blocked with $3 \% \mathrm{H}_{2} \mathrm{O}_{2}$. Sections were further blocked using 5\% horse serum in Tris-buffered saline for 30 mins. Samples were then incubated overnight in a dark box at 4oC in 1:300 primary monoclonal antibody directed against AR (Reference M3562; Lot 10114412; Dako UK Ltd. Monoclonal Mouse; Anti-Human; Androgen Receptor; Clone AR441; Isotope IgG1, kappa), diluted using DAKO antibody diluent (Reference S0809; Lot 10121673; Dako North America, Inc. 6392 Via Real Carpinteria, CA, 93013 USA). Bound antibody complex was visualised using EnVision plus kit (Dako UK Ltd.) followed by 3,3-diaminobenzidine tetrahydrochloride (DAB, Dako UK Ltd.). Tissue samples were counterstained with haematoxylin and blued with Scots Tap Water Substitute, dehydrated through graded alcohol and xylene and mounted with Di-N-Butyl Phthalate in xylene (DPX).

\section{Scoring}

TMAs were scanned using the Hamamatsu Nano Zoomer (Welwyn Gardens City, Hertfordshire, UK) at x 20 magnification, and visualisation was carried out using Slide path Digital Image Hub, version 4.0.1 (Leica Biosystems, UK). The weighted histoscore method (H-score system) was used to blind score the tissue staining intensity of AR by 2 independent observers blinded to the clinical data. Histoscores were calculated from the sum of ( $1 \mathrm{X} \%$ cells staining weakly positive $)+(2 \mathrm{X} \%$ cells staining moderately positive $)+(3 \mathrm{X} \%$ cells staining strongly positive) with a maximum of 300 . Each core has been scored and rescored by the researcher and $10 \%$ of scoring verified by an independent observer to ensure accuracy. The inter-class correlation coefficient (ICC) is calculated to confirm consistency 


\section{Cancer Therapy \& Oncology International Journal}

between observers, where the mean scores of the two observers will be used for analysis.

\section{Statistical Analysis}

Only patients with a score for AR were included in the analysis ( $\mathrm{n}=752$ ). Cut-off values for high or low protein expression were determined by the median of the average values of the intensity of staining. $10 \%$ cut-off was used in this paper analysis. The relationships between variables were assessed using contingency table analysis with the $\mathrm{X} 2$ test for linear trend. Results
Correlations coefficients were analysed using a Spearman's rho. Kaplan- Meier curves with log rank analysis was used to examine the effect of protein expression on cancer-specific survival (CSS). Univariate survival analysis was performed using Cox proportional hazards regression. Variables with P-value of $<0.05$ were entered a multivariable model using a backwards conditional method for all patients and triple negative patients. All statistical analyses were two-sided, and significance defined as $\mathrm{P}$-value $<0.05$. All statistical analysis was performed using the SPSS software version 22 (IBM SPSS, Chicago, IL, USA).

Table 1: The relationship between clinicopathological characteristics and AR status (full cohort).

\begin{tabular}{|c|c|c|c|c|}
\hline & N (\%) & $\begin{array}{c}\text { AR }-v e \\
n=293(39 \%)\end{array}$ & $\begin{array}{c}A R+v e \\
n=459(61 \%)\end{array}$ & P-value \\
\hline Age $(\leq 50 />50$ years $)$ & $224(30 \%) / 528(70 \%)$ & $96 / 197$ & $128 / 331$ & 0.154 \\
\hline Size $(\leq 20 / 21-50 />50 \mathrm{~mm})$ & $241(56 \%) / 289(38 \%) / 41(6 \%)$ & $165 / 115 / 13$ & $256 / 174 / 28$ & 0.640 \\
\hline Grade (I / II / III) & $132(18 \%) / 332(44 \%) / 287(38 \%)$ & $36 / 112 / 114$ & $96 / 220 / 143$ & $<0.001$ \\
\hline Lymph node (negative/positive) & $417(56 \%) / 323(43 \%)$ & $161 / 129$ & $256 / 194$ & 0.714 \\
\hline ER status (no/yes) & $251(33 \%) / 499(66 \%)$ & $158 / 135$ & $93 / 364$ & $<0.001$ \\
\hline PR status (no/yes) & $402(54 \%) / 348(46 \%)$ & $203 / 90$ & $199 / 258$ & $<0.001$ \\
\hline Her2 status (no/ yes) & $612(81 \%) / 126(17 \%)$ & $232 / 52$ & $380 / 74$ & 0.480 \\
\hline $\begin{array}{l}\text { Molecular subtypes (luminal A/luminal B/ Her2 like/ } \\
\text { TNBC) }\end{array}$ & $330(44 \%) / 167(22 \%) / 72(10 \%) /$ & & & \\
\hline $160(21 \%)$ & $83 / 50 / 38 / 110$ & $247 / 117 / 34 / 50$ & $<0.001$ & \\
\hline Tumour necrosis (low/high) & $372(49 \%) / 358(48 \%)$ & $117 / 172$ & $225 / 186$ & $<0.001$ \\
\hline Klintrup-Mäkinen grade (no/any) & $120(16 \%) / 610(81 \%)$ & $21 / 265$ & $99 / 345$ & $<0.001$ \\
\hline Tumour-stroma percentage (low/high) & $511(68 \%) / 224(30 \%)$ & $200 / 89$ & $311 / 135$ & 0.880 \\
\hline Tumour budding (low/high) & $493(66 \%) / 242(32 \%)$ & $214 / 75$ & $279 / 167$ & 0.001 \\
\hline Endocrine therapy (none/tamoxifen/ATAC) & $130(17 \%) / 459(61 \%) / 29(4 \%)$ & $81 / 168 / 0$ & $49 / 291 / 29$ & $<0.001$ \\
\hline Adjuvant chemotherapy (no/yes) & $440(59 \%) / 310(41 \%)$ & $136 / 155$ & $304 / 155$ & $<0.001$ \\
\hline Adjuvant radiotherapy (no/yes) & $397(53 \%) / 353(47 \%)$ & $155 / 136$ & $242 / 217$ & 0.885 \\
\hline Survival (alive/cancer death/non cancer death) & $424(56 \%) / 165(22 \%) / 144(19 \%)$ & $165 / 61 / 58$ & $259 / 104 / 86$ & 0.649 \\
\hline Luminal A $(n=330)$ & & $\mathrm{n}=83(25 \%)$ & $n=247(75 \%)$ & \\
\hline Tumour budding (low/high) & & $58 / 23$ & $135 / 101$ & 0.022 \\
\hline Endocrine therapy (none/tamoxifen/ATAC) & & $8 / 72 / 0$ & $18 / 178 / 17$ & 0.057 \\
\hline Adjuvant chemotherapy (no/ yes) & & $51 / 31$ & $184 / 63$ & 0.033 \\
\hline Luminal B ( $n=167)$ & & $n=50(30 \%)$ & $n=117(70 \%)$ & \\
\hline Necrosis (low/high) & & $20 / 29$ & $65 / 50$ & 0.066 \\
\hline Klintrup-Mäkinen grade (no/any) & & $3 / 46$ & $33 / 84$ & 0.002 \\
\hline Her-2 like $(n=72)$ & & $\mathrm{n}=38(53 \%)$ & $\mathrm{n}=34(47 \%)$ & \\
\hline Tumour budding (low/high) & & $24 / 14$ & $29 / 5$ & 0.035 \\
\hline Triple negative $(n=160)$ & & $n=110(69 \%)$ & $n=50(31 \%)$ & \\
\hline Tumour budding (low/high) & & $90 / 19$ & $33 / 16$ & 0.034 \\
\hline Adjuvant chemotherapy (no/yes) & & $35 / 74$ & $24 / 26$ & 0.055 \\
\hline
\end{tabular}

In molecular subtypes only, variables with association are shown.

Only patients with staining for AR were included in the analysis ( $\mathrm{n}=752)$. Table 1 summarises clinicopathological characteristics of patients. Most of the patients (70\%) were above 50 years old, had small tumour size $\leq 20 \mathrm{~mm} \mathrm{(56 \% ),} \mathrm{had}$ grade II and III tumours (82\%) and no involved lymph nodes (56\%). ER positive tumours (66\%), PR negative tumours (53\%) and HER2 negative tumours (81\%) formed most tumours. 81\% of patients had positive Klintrup-Makinen (KM) grade, 32\% 


\section{Cancer Therapy \& Oncology International Journal}

had high tumour budding and 30\% had high TSP. $459(61 \%)$ of the patients received endocrine therapy, 29 (4\%) of patients received aromatase inhibitor treatment, and 310 (41\%) of patients received adjuvant chemotherapy. The median survival was 149 months with 165 deaths from breast cancer. Number of events was 46 in luminal A, 30 in luminal B, 24 in Her2 like and 46 in TNBC.

AR expression at cut-off $10 \%$ were identified in 459 (61\%)

(61\%)

\begin{tabular}{|c|c|c|c|c|}
\hline & \multicolumn{2}{|c|}{ Univariate Analysis } & \multicolumn{2}{|c|}{ Multivariate Analysis } \\
\hline & Hazard Ratio (95\% CI) & P-value & Hazard Ratio (95\% CI) & P-value \\
\hline Age $(<50 />50$ years $)$ & $1.19(0.63-2.27)$ & 0.589 & & \\
\hline Size $(\leq 20 / 21-50 />50 \mathrm{~mm})$ & $1.85(1.09-3.13)$ & 0.022 & $1.81(1.33-2.45)$ & $<0.001$ \\
\hline Grade (I / II / III) & $1.89(1.16-3.08)$ & 0.010 & $1.69(1.20-2.36)$ & 0.003 \\
\hline Involved lymph node (no/yes) & $2.58(1.39-4.79)$ & 0.003 & $1.89(1.22-2.93)$ & 0.004 \\
\hline ER receptor status (no/yes) & $0.44(0.24-0.83)$ & 0.010 & & 0.836 \\
\hline PR receptor status (no/yes) & $0.46(0.22-0.94)$ & 0.035 & & 0.130 \\
\hline Her2 status (no/yes) & $1.73(0.18-4.19)$ & 0.325 & & \\
\hline Tumour necrosis (low/high) & $4.51(2.02-10.09)$ & $<0.001$ & $2.056(1.31-3.22)$ & 0.002 \\
\hline Klintrup-Mäkinen grade (no/any) & $1.43(0.79-2.57)$ & 0.232 & & \\
\hline Tumour stroma percentage (low/high) & $2.06(1.15-3.69)$ & 0.115 & & \\
\hline Tumour budding (low/high) & $2.20(1.23-3.94)$ & 0.007 & $1.95(1.28-2.98)$ & 0.002 \\
\hline Endocrine therapy (none/tamoxifen/ATAC) & $2.38(1.15-4.94)$ & 0.520 & & \\
\hline Adjuvant chemotherapy (no/yes) & $1.93(1.36-2.84)$ & 0.001 & & 0.160 \\
\hline
\end{tabular}

Table 3 : The relationship between clinicopathological characteristics and cancer specific survival in patients with AR-ve group ( $n=293$ ).

\begin{tabular}{|c|c|c|c|c|}
\hline & \multicolumn{2}{|c|}{ Univariate Analysis } & \multicolumn{2}{c|}{ Multivariate Analysis } \\
\hline & Hazard Ratio (95\% CI) & P-value & Hazard Ratio (95\% CI) & P-value \\
\hline Age $(<50 />50$ years) & $1.34(0.53-3.41)$ & 0.589 & & 0.154 \\
\hline Size $(\leq 20 /$ 21-50/ $>50 ~ m m)$ & $1.66(1.10-2.50)$ & 0.015 & & 0.180 \\
\hline Grade (I / II / III) & $1.96(1.26-3.04)$ & 0.003 & & $<0.001$ \\
\hline Involved lymph node (no/yes) & $3.24(1.88-5.57)$ & 0.003 & $2.97(1.70-5.19)$ & 0.157 \\
\hline ER receptor status (no/yes) & $0.51(0.30-0.87)$ & 0.014 & & 0.117 \\
\hline PR receptor status (no/yes) & $0.54(0.29-0.99)$ & 0.048 & & 0.606 \\
\hline Her2 status (no/yes) & $1.81(1.02-3.21)$ & 0.043 & & $<0.001$ \\
\hline Tumour necrosis (low/high) & $3.41(1.77-6.54)$ & $<0.001$ & $3.21(1.66-6.17)$ & \\
\hline Klintrup-Mäkinen grade (no/any) & $0.73(0.29-1.82)$ & 0.232 & & $<0.001$ \\
\hline Tumour stroma percentage (low/high) & $2.42(1.46-3.99)$ & 0.001 & $2.10(1.26-3.51)$ & \\
\hline Tumour budding (low/high) & $1.64(0.97-2.79)$ & 0.064 & & \\
\hline Endocrine therapy (none/tamoxifen/ATAC) & $0.76(0.43-1.35)$ & 0.353 & & \\
\hline Adjuvant chemotherapy (no/yes) & $1.85(1.08-3.17)$ & 0.023 & & \\
\hline
\end{tabular}

Patients were then stratified according to AR status into $\mathrm{AR}+\mathrm{ve}$ and $\mathrm{AR}$-ve groups and the relationship between clinicopathological characteristics and cancer specific survival were examined in both groups (Tables $2 \& 3$ ). In AR +ve patients, tumour size $(\mathrm{p}<0.001)$, grade $(\mathrm{P}=0.003)$ and lymph node $(\mathrm{P}=0.004)$ were independently associated with CSS as well as tumour necrosis and budding (both $\mathrm{P}=0.002$ ). The hazard ratio (1.95) of tumour budding was stronger than that for size (1.81),

grade (1.69), and lymph node (1.89) the most useful pathological variables for breast cancer prognosis in $\mathrm{AR}+$ ve group. In AR ve patients, lymph node $(\mathrm{p}<0.001)$, tumour necrosis $(\mathrm{p}<0.001)$ and tumour stroma percentage $(\mathrm{p}<0.001)$ were independent prognostic factors of poor CSS.

As AR was associated with molecular subtype Table 1, patients were stratified into molecular subtypes, luminal A $(n=330)$, luminal B $(n=167)$, Her2 like $(n=72)$ and TNBC 
( $n=160$ ). In luminal A tumours, AR was significantly associated with increased tumour budding $(\mathrm{p}=0.022)$ and reduced adjuvant chemotherapy ( $p=0.033)$. In luminal $B, A R$ was significantly associated with weak Klintrup-Makinen (KM) grade ( $p=0.002)$. AR was significantly associated with reduced tumour budding in Her2 like ( $p=0.035)$, and increased tumour budding in TNBC $(\mathrm{p}=0.034)$.

\section{The relationship Between $A R$ and survival outcome}

Kaplan-Meier survival curves show that AR expression in the whole cohort was not associated with CSS $(\mathrm{P}=0.713)$ Figure 1. AR was significantly associated with CSS in luminal A ( $\mathrm{P}=0.028)$ and $\mathrm{TNBC}(\mathrm{P}=0.013)$ Figure 2. In contrast, in patients with luminal B and Her2 like tumours the correlation was lost, and no associations were seen $(\mathrm{P}=0.916$ and $\mathrm{P}=0.195$ respectively). Therefore, further survival analysis was not carried out for those subtypes. In univariate analysis for luminal A, and for TNBC AR was significantly associated with $\operatorname{CSS}(\mathrm{P}=0.028$ and $\mathrm{P}=0.013$ respectively) (Tables $4 \& 5$ ). In multivariate analysis for luminal A, AR $(\mathrm{P}=0.046)$, size $(\mathrm{P}=0.005)$, grade $(\mathrm{P}=0.028)$ and lymph node $(\mathrm{P}=0.013)$ were independent prognostic factors (Table 4 ).
In multivariate analysis for TNBC, size $(\mathrm{p}<0.001)$, lymph node $(\mathrm{P}=0.001)$, tumour necrosis $(\mathrm{P}=0.007)$, and tumour budding $(\mathrm{P}=0.008)$ were independent prognostic factors. However, AR does not appear to be independently prognostic in these patients ( $\mathrm{p}=0.357)$ (Table 5).

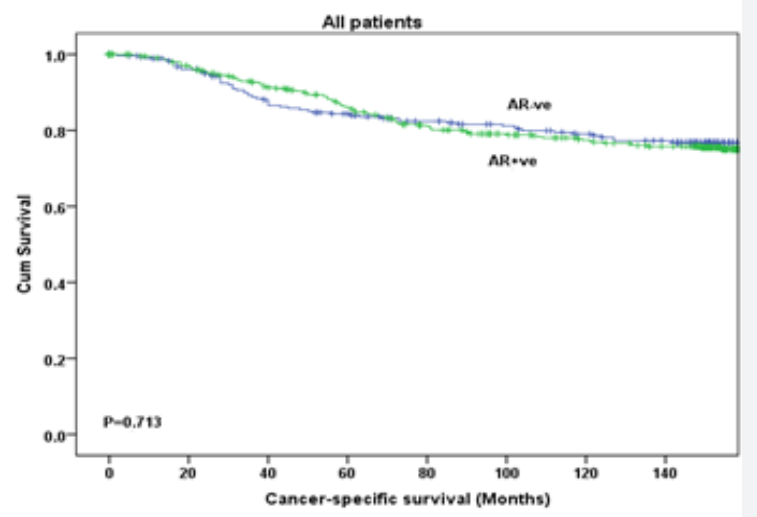

Figure 1: Kaplan-Meier survival curves (Log rank) of cancer specific survival) in all patients $P=0.713$

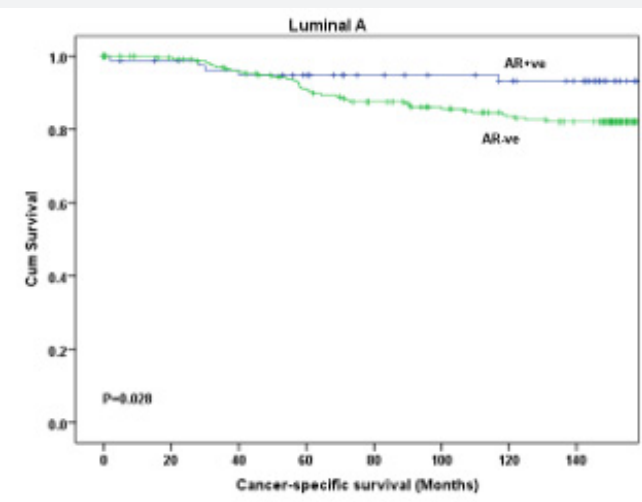

A

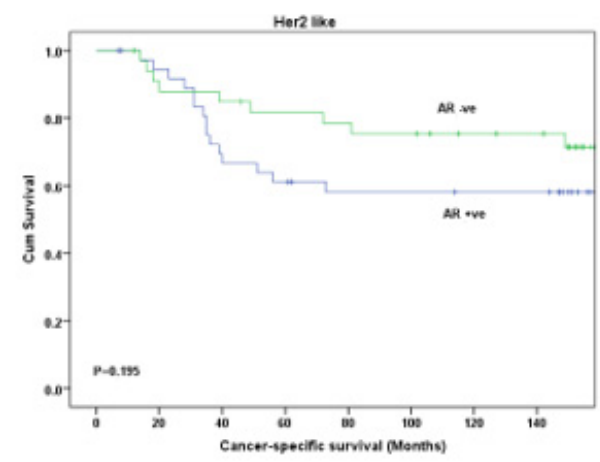

D

C

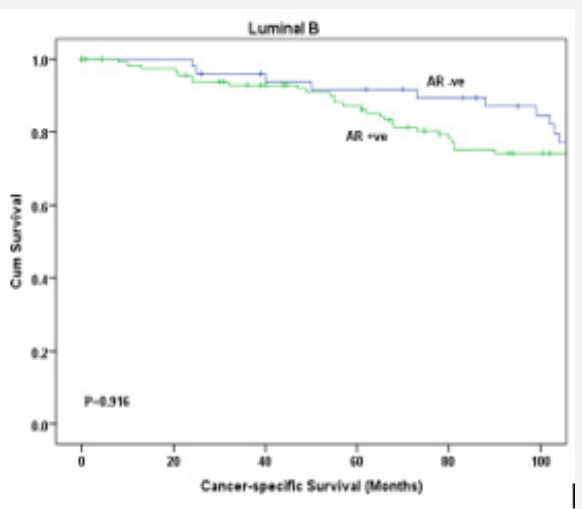

B

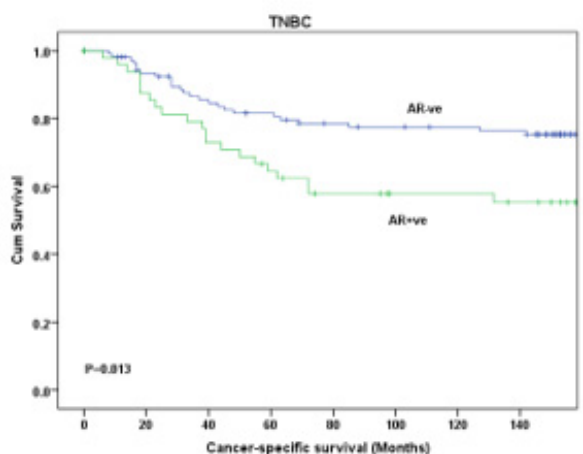

Figure 2: Kaplan-Meier survival curves (Log rank) of cancer specific survival in different molecular subtypes $(A)$ Luminal $A P=0.028$ (B) Luminal B $\mathrm{P}=0.916$ (C) Her2 like $\mathrm{P}=0.195$ (D) Triple negative $\mathrm{P}=0.013$.

\section{Discussion}

The results of present study have shown that AR expression in breast cancer was associated with tumour budding and poor survival outcome particularly in TNBC. However, the prognostic of AR was not independent of the prognostic value of tumour budding. This may suggest that AR was a regulator of tumour budding and therefore a potential therapeutic target in patients with TNBC patients. In this study and with a cut-off value of 


\section{Cancer Therapy \& Oncology International Journal}

$10 \%$, AR was positive in more than $60 \%$ of patients $(>70 \%$ in luminal $\mathrm{A}$ and $\mathrm{B}, 47 \%$ for Her2 like and $31 \%$ for TNBC). This observation was consistent with previous reports $[8,13,17,27$ 29]. The basis of phenotypic and survival effects was subtypedependent. In TNBC we observed that increased expression of AR was significantly associated with reduced CSS. Previous reports also have shown that AR expression in ER negative tumours and TNBC were associated with higher nuclear grade, increased risk of mortality and reduced survival [15-17,29,30] consistent with our results. The unfavourable association between AR expression and outcome in TNBC may be due to AR expression increasing the dissociation of tumour cells via up-regulation of tumour budding. In AR +ve tumours, tumour budding was an independent prognostic factor of CSS (Table 2) compared with that of AR -ve group (Table 3).

Table 4: The relationship between clinicopathological characteristics and cancer specific survival in Luminal A ( $n=303)$.

\begin{tabular}{|c|c|c|c|c|}
\hline & \multicolumn{2}{|c|}{ Univariate Analysis } & \multicolumn{2}{|c|}{ Multivariate Analysis } \\
\hline & Hazard Ratio (95\% CI) & P-value & Hazard Ratio (95\% CI) & P-value \\
\hline Age $(<50 />50$ years $)$ & $1.51(0.72-3.17)$ & 0.279 & & \\
\hline Size $(\leq 20 / 21-50 />50 \mathrm{~mm})$ & $2.17(1.43-3.30)$ & $<0.001$ & $1.93(1.02-6.59)$ & 0.005 \\
\hline Grade (I / II / III) & $1.94(1.22-3.06)$ & 0.005 & $1.76(1.06-2.92)$ & 0.028 \\
\hline Involved lymph node (no/yes) & $3.03(1.63-5.64)$ & $<0.001$ & $2.27(1.19-4.30)$ & 0.013 \\
\hline Androgen receptor (low/high) & $2.72(1.07-6.89)$ & 0.028 & $2.58(1.02-6.59)$ & 0.046 \\
\hline Tumour necrosis (low/high) & $2.16(1.19-3.90)$ & 0.011 & & 0.158 \\
\hline Klintrup-Mäkinen grade (week/strong) & $0.85(0.43-1.63)$ & 0.644 & & \\
\hline Tumour stroma percentage (low/high) & $1.74(0.96-3.15)$ & 0.067 & & 0.194 \\
\hline Tumour budding (low/high) & $1.23(0.68-2.21)$ & 0.494 & & \\
\hline Endocrine therapy (none/tamoxifen/ATAC) & $0.63(0.80-1.54)$ & 0.667 & & \\
\hline Adjuvant chemotherapy (no/yes) & $1.82(1.02-3.24))$ & 0.044 & & 0.803 \\
\hline
\end{tabular}

It is of interest that, in this study, AR was consistently associated with increased tumour budding in all patients and different subgroups. To best of our knowledge this is the first breast cancer study to report an association between AR and tumour budding in clinical settings. With increased appreciation of the importance of the tumour budding in cancer progression $[25,31]$ this positive relationship between AR and budding might provide some clarification of the poor outcome that
TNBC patients' experience. It was also interesting that tumour budding was shown to be an independent prognostic factor in TNBC, suggesting a link between AR stimulation and epithelial mesenchymal transition (EMT) the molecular form of tumour budding [31] potentially via AR up-regulation of ZEB2 [32] and suppression of E-cadherin [33,34]. Also, AR may have EMTpromoting effects even independently of EMT transcription factors [35].

Table 5: The relationship between clinicopathological characteristics and cancer specific survival in TNBC $(n=160)$.

\begin{tabular}{|c|c|c|c|c|}
\hline & \multicolumn{2}{|c|}{ Univariate Analysis } & \multicolumn{2}{|c|}{ Multivariate Analysis } \\
\hline & Hazard Ratio (95\% CI) & P-value & Hazard Ratio (95\% CI) & P-value \\
\hline Age $(<50 />50$ years $)$ & $1.51(0.72-3.17)$ & 0.279 & & \\
\hline Size $(\leq 20 / 21-50 />50 \mathrm{~mm})$ & $3.54(2.11-5.95)$ & $<0.001$ & $2.66(1.55-4.58)$ & $<0.001$ \\
\hline Grade (I / II / III) & $0.86(1.07-0.52)$ & 0.858 & & \\
\hline Involved lymph node (no/yes) & $4.53(2.34-8.76)$ & $<0.001$ & $3.29(1.67-6.56)$ & 0.001 \\
\hline Androgen receptor (low/high) & $2.06(1.15-3.07)$ & 0.013 & & 0.357 \\
\hline Tumour necrosis (low/high) & $6.03(1.86-19.46)$ & 0.003 & $5.21(1.58-17.12)$ & 0.007 \\
\hline Klintrup-Mäkinen grade (week/strong) & $0.67(0.34-1.45)$ & 0.335 & & \\
\hline Tumour stroma percentage (low/high) & $2.05(1.12-3.78)$ & 0.021 & & 0.101 \\
\hline Tumour budding (low/high) & $2.84(1.56-5.16)$ & 0.001 & $2.42(1.25-4.68)$ & 0.008 \\
\hline Endocrine therapy (none/tamoxifen/ATAC) & $0.85(0.40-1.17)$ & 0.667 & & \\
\hline Adjuvant chemotherapy (no/yes) & $1.12(0.60-2.07)$ & 0.714 & & \\
\hline
\end{tabular}

Because TNBC have relatively aggressive tumour biology and limited treatment, the result of this study would support the use of AR-targeted drugs as a potential therapeutic target for this subgroup [7,36]. This study shows that increased AR expression in TNBC was a marker of poor outcome and had a potential crosstalk link with the aggressiveness of this subgroup through increasing tumour dissociation and spread (tumour budding). AR-targeted drugs are effective therapeutic target for prostate 


\section{Cancer Therapy \& Oncology International Journal}

cancer and have been approved for treatment of castrateresistant prostate cancer [37]. Enzalutamide, a nonsteroidal inhibitor of nuclear localization of AR, was significantly improved overall survival in castrate-resistant prostate cancer $[37,38]$.

Results from clinical trial examining the utility of enzalutamide in advanced TNBC has showed improved overall survival in patients with AR + ve tumours compared to those with AR -ve tumours, further suggesting AR as a potential therapeutic target in TNBC (clinicaltrials.gov: NCT01889238). In addition, a phase II trial of bicalutamide, an androgen antagonist, has shown a clinical benefit rate of $19 \%$ in a select group of patients with hormone receptor negative, AR positive breast cancer [39]. It has also shown that combining anti-androgens with a PI3K inhibitor increases their sensitivity in TNBC patients [40].

In this study we also observed that in luminal A tumours increased AR expression leads to reduced CSS independent of other variables. This detrimental effect of AR on survival suggests that anti-androgen therapy may be of therapeutic benefit to patients with luminal disease. It was reported that when Tamoxifen-resistant breast cancer cells that expressed high levels of AR were exposed to bicalutamide (antiandrogen), cell growth was shown to decrease as well as reversing Tamoxifen resistance [41]. Therefore, antiandrogen treatment would be an effective therapeutic strategy for luminal cancers with Tamoxifen resistance. In addition, although not significant a trend was observed with better survival on AR positive Her2 like patients and therefore AR should not be targeted in this group.

In conclusion, this study shows unfavourable impacts of $A R$ expression in breast cancer patients. In both luminal A (ER+ve) and TNBC (ER-ve), AR conveys a poor effect. This is potentially attributable to up-regulation of tumour budding within the tumour microenvironment. This suggests that AR may be an important regulator of tumour cells dissociation and migration in breast cancer. These data also suggest that AR is a potential prognostic biomarker for TNBC. Further investigation is now needed to define how AR is influencing tumour budding, is it a direct association or is another factor involved.

\section{Additional Information}

Ethics approval and consent to participate: Institutional Review Board approval for use of human tissue in this study was given by the Research Ethics Committee of the North Glasgow University Hospitals NHS Trust.

\section{Consent for publication}

$\mathrm{N} / \mathrm{A}$.

\section{Availability of data and material}

N/A.

\section{Conflict of interest}

None.

\section{Funding}

This research did not receive any specific grant from funding agencies in the public, commercial, or not-for-profit sectors.

\section{Authors' Contributions}

Study concepts and design, Fadia Gujam, Katie Dickson and Joanne Edwards.

Data acquisition, Katie Dickson and Pamela McCall.

Data analysis and interpretation, Fadia Gujam, Pamela McCall, Joanne Edwards and Donald McMillan.

Statistical analysis, Fadia Gujam.

Manuscript preparation, Fadia Gujam.

Manuscript editing, Joanne Edwards and Donald McMillan.

Manuscript review, all authors.

\section{Acknowledgement}

Authors would thank Glasgow Bio-bank for providing tissue materials.

\section{References}

1. Henderson BE, Feigelson HS (2000) Hormonal carcinogenesis Carcinogenesis 21(3): 427-433.

2. Sherry MM, Greco FA, Johnson DH, Hainsworth JD (1986) Metastatic breast cancer confined to the skeletal system. An indolent disease. Am J Med 81(3): 381-386

3. Perou CM, Sorlie T, Eisen MB, van de Rijn M, Jeffrey S, et al. (2000) Molecular portraits of human breast tumours. Nature 406: 747-752.

4. Lehmann BD, Bauer JA, Chen X, Sanders ME, Chakravarthy AB, et al. (2011) Identification of human triple-negative breast cancer subtypes and preclinical models for selection of targeted therapies. J Clin Invest 121(7): 2750-2767.

5. Smith I, Procter M, Gelber RD, Guillaume S, Feyereislova A, et al. (2007) 2-year follow-up of trastuzumab after adjuvant chemotherapy in HER2-positive breast cancer: a randomised controlled trial. Lancet 369(9555): 29-36.

6. Nakai K, Hung MC, Yamaguchi H (2016) A perspective on anti-EGFR therapies targeting triple-negative breast cancer. American journal of cancer research 6(8): 1609-1623.

7. Kono M, Fujii T, Lim B, Karuturi MS, Tripathy D, et al. (2017) Androgen Receptor Function and Androgen Receptor-Targeted Therapies in Breast Cancer: A Review. JAMA oncology 3(9): 1266-1273.

8. Collins LC, Cole KS, Marotti JD, Hu R, Schnitt SJ, et al. (2011) Androgen receptor expression in breast cancer in relation to molecular phenotype: results from the Nurses' Health Study. Mod Pathol 24(7): 924-931.

9. Guedj M, Marisa L, de Reynies A, Orsetti B, Schiappa R, et al. (2012) A refined molecular taxonomy of breast cancer. Oncogene 31(9): 1196206.

10.Wong YC, Xie B (2001) The role of androgens in mammary carcinogenesis. Ital J Anat Embryol 106: 111-125.

11. Robinson JL, Macarthur S, Ross-Innes CS, Tilley WD, Neal DE, et al (2011) Androgen receptor driven transcription in molecular apocrine breast cancer is mediated by FoxA1. EMBO J 30(15): 3019-3027. 


\section{Cancer Therapy \& Oncology International Journal}

12. Moe RE, Anderson BO (2007) Androgens and androgen receptors: clinically neglected sector in breast cancer biology. J Surg Oncol 95(6) 437-439.

13. Niemeier LA, Dabbs DJ, Beriwal S, Striebel JM, Bhargava R (2010) Androgen receptor in breast cancer: expression in estrogen receptorpositive tumors and in estrogen receptor-negative tumors with apocrine differentiation. Mod Pathol 23(2): 205-212.

14. Gucalp A, Tolaney S, Isakoff S (2012) Targeting the androgen receptor (AR) in women with AR+ ER-/PR- metastatic breast cancer (MBC). J Clin Oncol 30(Suppl): 1006.

15. Farmer P, Bonnefoi H, Becette V, Tubiana-Hulin M, Fumoleau P, et al. (2005) Identification of molecular apocrine breast tumours by microarray analysis. Oncogene 24(29): 4660-4671.

16. Hu R, Dawood S, Holmes MD, Collins LC, Schnitt SJ, et al. (2011) Androgen receptor expression and breast cancer survival in postmenopausal women. Clin Cancer Res 17(7): 1867-1874.

17. Choi JE, Kang SH, Lee SJ, Bae YK (2015) Androgen receptor expression predicts decreased survival in early stage triple-negative breast cancer. Ann Surg Oncol 22(1): 82-89.

18. McAllister SS, Weinberg RA (2014) The tumour-induced systemic environment as a critical regulator of cancer progression and metastasis. Nat Cell Biol 16(18): 717-27.

19. Hanahan D, Weinberg RA (2011) Hallmarks of cancer: the next generation. Cell 144(5): 646-674.

20. Grigore AD, Jolly MK, Jia D, Farach-Carson MC, Levine H (2016) Tumor Budding: The Name is EMT. Partial EMT. J Clin Med 5(5): E51.

21. Mohammed Z, Edwards J, Orange C, Mallon E, Doughty JC, et al. (2012) Breast cancer outcomes by steroid hormone receptor status assessed visually and by computer image analysis. Histopathology 61(2): 283292

22. Klintrup K, Makinen JM, Kauppila S, Vare PO, Melkko J, et al. (2005) Inflammation and prognosis in colorectal cancer. Eur J Cancer 41(17): 2645-2654.

23. Gujam FJ, Edwards J, Mohammed ZM, Going JJ, McMillan DC (2014) The relationship between the tumour stroma percentage, clinicopathological characteristics and outcome in patients with operable ductal breast cancer. British journal of cancer 111(1): 157165

24. Gujam FJ, McMillan DC, Mohammed ZM, Edwards J, Going JJ (2015) The relationship between tumour budding, the tumour microenvironment and survival in patients with invasive ductal breast cancer. Br J Cancer 113(7): 1066-1074

25. Edwards J, Krishna N, Grigor KM, Bartlett JM (2003) Androgen receptor gene amplification and protein expression in hormone refractory prostate cancer. Br J Cancer 89: 552-556.

26. Gonzalez LO, Corte MD, Vazquez J, Sara Junquera, Rosario Sanchez, et al. (2008) Androgen receptor expresion in breast cancer: relationship with clinicopathological characteristics of the tumors, prognosis, and expression of metalloproteases and their inhibitors. BMC Cancer 8: 149.
27. He J, Peng R, Yuan Z, Wang S, et al. (2012) Prognostic value of androgen receptor expression in operable triple-negative breast cancer: a retrospective analysis based on a tissue microarray. Med Oncol 29(2): 406-410.

28. Jiang HS, Kuang XY, Sun WL, Xu Y, Zheng YZ, et al. (2016) Androgen receptor expression predicts different clinical outcomes for breast cancer patients stratified by hormone receptor status. Oncotarget 7(27): 41285 .

29. Agoff SN, Swanson PE, Linden H, Hawes SE, Lawton TJ (2003) Androgen receptor expression in estrogen receptor-negative breast cancer. Immunohistochemical, clinical, and prognostic associations. Am J Clin Pathol 120(5): 725-731.

30. Dawson H, Lugli A (2015) Molecular and pathogenetic aspects of tumour budding in colorectal cancer. Front Med (Lausanne) 2: 11.

31. Jacob S, Nayak S, Fernandes G, Barai RS, Menon S, et al. (2014) Androgen receptor as a regulator of ZEB2 expression and its implications in epithelial-to-mesenchymal transition in prostate cancer. Endocr Relat Cancer 21(3): 473-486.

32. Liu YN, Liu Y, Lee HJ, Hsu YH, Chen JH (2008) Activated androgen receptor downregulates E-cadherin gene expression and promotes tumor metastasis. Mol Cell Biol 28: 7096-7108.

33. Nakazawa M, Kyprianou N (2017) Epithelial-mesenchymal-transition regulators in prostate cancer: Androgens and beyond. J Steroid Biochem Mol Biol 166: 84-90.

34. Voutsadakis IA (2016) Epithelial-mesenchymal transition (EMT) and regulation of EMT factors by steroid nuclear receptors in breast cancer: a review and in silico investigation. J Clin Med 5(1): 11

35. De Amicis F, Thirugnansampanthan J, Cui Y, Selever J, Beyer A, et al. (2010) Androgen receptor overexpression induces tamoxifen resistance in human breast cancer cells. Breast Cancer Res Treat 121(1): 1-11.

36. Barton VN, Gordon MA, Richer JK, Elias A (2016) Anti-androgen therapy in triple-negative breast cancer. Ther Adv Med Oncol 8: 305308.

37. Scher HI, Fizazi K, Saad F, Taplin ME, Sternberg CN, et al. (2012) Increased survival with enzalutamide in prostate cancer after chemotherapy. N Engl J Med 367(13): 1187-1197.

38. Wong YN, Ferraldeschi R, Attard G, de Bono J (2014) Evolution of androgen receptor targeted therapy for advanced prostate cancer. Nat Rev Clin Oncol 11(6): 365-376.

39. Gucalp A, Tolaney S, Isakoff SJ, Ingle JN, Liu MC, et al. (2013) Phase II trial of bicalutamide in patients with androgen receptor-positive, estrogen receptor-negative metastatic Breast Cancer. Clin Cancer Res 19(19): 5505-5512

40. Lehmann BD, Bauer JA, Schafer JM, Pendleton CS, Tang L, et al. (2014) PIK3CA mutations in androgen receptor-positive triple negative breast cancer confer sensitivity to the combination of PI3K and androgen receptor inhibitors. Breast Cancer Res 16(4): 406.

41. Cochrane DR, Bernales S, Jacobsen BM, Cittelly DM, Howe EN, et al. (2014) Role of the androgen receptor in breast cancer and preclinical analysis of enzalutamide. Breast Cancer Res 16(1): R7. 
Your next submission with Juniper Publishers will reach you the below assets

- Quality Editorial service

- Swift Peer Review

- Reprints availability

- E-prints Service

- Manuscript Podcast for convenient understanding

- Global attainment for your research

- Manuscript accessibility in different formats

( Pdf, E-pub, Full Text, Audio)

- Unceasing customer service

Track the below URL for one-step submission https://juniperpublishers.com/online-submission.php 